\title{
Influence of Incorporating Silver Nanoparticles in Protease Treatment on Fiber Friction, Antistatic, and Antibacterial Properties of Wool Fibers
}

\author{
Hafeezullah Memon $\mathbb{D}^{1,2}$ Hua Wang ${ }^{1},{ }^{3}$ Sohail Yasin, ${ }^{4}$ and Adeel Halepoto ${ }^{5}$ \\ ${ }^{1}$ Donghua University Center for Civil Aviation Composites, Donghua University, 2999 North Renmin Road, \\ Shanghai 201620, China \\ ${ }^{2}$ Key Laboratory of Textile Science \& Technology, Ministry of Education, College of Textiles, Donghua University, \\ 2999 North Renmin Road, Shanghai 201620, China \\ ${ }^{3}$ College of Textiles, Donghua University, 2999 North Renmin Road, Shanghai 2011620, China \\ ${ }^{4}$ School of Textiles and Design, Heriot-Watt University, Galashiels TD1 3HF, UK \\ ${ }^{5}$ College of Chemistry, Chemical Engineering, and Biotechnology, Donghua University, Shanghai 201620, China
}

Correspondence should be addressed to Hua Wang; huawang@dhu.edu.cn

Received 7 August 2018; Revised 9 October 2018; Accepted 21 October 2018; Published 2 December 2018

Academic Editor: Jean-Marie Nedelec

Copyright (C) 2018 Hafeezullah Memon et al. This is an open access article distributed under the Creative Commons Attribution License, which permits unrestricted use, distribution, and reproduction in any medium, provided the original work is properly cited.

\begin{abstract}
This study was conducted by analyzing the effect of surface treatment on wool using varying percentages of protease $(3 \%, 6 \%$, and 9\%) with incorporating silver nanoparticles and by varying $\mathrm{pH}$ (i.e., $\mathrm{pH}=4$ and $\mathrm{pH}=7$ ). The comparison of fiber surface morphology and the FTIR analysis was done to characterize the nanocoating. The results showed that the antistatic and antibacterial effect on the samples treated at 3\% protease and 6\% protease were better than the samples treated at $9 \%$ protease. Correspondingly, the samples treated at $\mathrm{pH} 4$ had better antistatic and antibacterial properties than those treated at $\mathrm{pH}$ 7. Sulfur compounds play a key role in interaction and absorption of silver nanoparticles.
\end{abstract}

\section{Introduction}

Despite many available synthetic fibers today, the natural fibers are still highly demanded and preferred to be used. Among other natural fibers, wool fiber is also being chosen by most of the consumers as one of the significant natural fibers. The livestock industry is not only established for meat and milk, but they also provide wool or hair fibers and thus affect positively the income of any country or state [1]. Regardless of high market demand, wool fiber is unsuccessful for being used as topmost fiber due to its dearth [2]. Pristine wool fiber comes with more or less major deficiencies, i.e., natural hydrophobicity of the outer surface due to the fatty acid layer, surface roughness due to its structure of cuticle, and a good media for the growth and propagation of bacteria under appropriate temperature and humidity. For the former two, several techniques have been applied to decompose the fatty surface layer [3-5] and/or coating or fabricating the hydrophilic materials over the layer of fatty acids on the surface wool fibers [6-8]. However, such treatments often cause some losses in mechanical properties and/or compromise on its natural feel and comfort.

The natural hydrophobicity of wool fiber causes the static charge build-up on the fiber surface. Antistatic treatments of wool textiles lower the electrical resistivity and facilitate the charge dissipation on the fiber and thus diminish the high potential electrical discharges. Moreover, by lowering the surface resistivity of wool textile materials, better soil release, electroconducting, and electromagnetic and thermal shielding properties can be achieved, as well. $\mathrm{Ki}$ et al. [9] maintained that the antistatic efficacy of the 
finished wool fabrics with AgNPs on their surface increased marginally up to $50 \mathrm{ppm}$, then, it was found to be decreased on further adding of AgNPs. Recently, a novel way of producing antistatic wool textiles by in situ polypyrrole (PPy) synthesis and its treatments on the wool textile surface has been studied [10]. Furthermore, Wang et al. [11] pretreated polyester fabrics then coated single-walled carbon nanotube (SWCNT) by coating-drying-curing under various plasma conditions and found that the appropriate conditions should be used to optimize the antistatic property of polyester fabrics.

Not only on the wool, but also on other textile media, some studies have been made to make the fiber antimicrobial. Dubas et al. [12] immobilized the antimicrobial silver nanoparticles (AgNPs) on nylon and silk fibers by following a sequential dipping in dilute solutions of AgNPs capped with poly (methacrylic acid) and poly (diallyl dimethyl ammonium chloride) by using the layer-by-layer deposition method. They maintained that $80 \%$ bacteria reduction for the silk fiber and 50\% for the nylon fiber was achieved by the formation of a colored thin film. KhalilAbad and Yazdanshenas [13] produced silver particles on cotton fibers by treatment with aqueous $\mathrm{KOH}$ and $\mathrm{AgNO}_{3}$, followed by surface hydrophobization. The modified cotton textiles were capable of killing both Gram-negative and Gram-positive bacteria on the textile surface.

Yu et al. [14] synthesized silver nanoparticles (AgNPs) by natural Dolcetto grape leaves and fabricated them with alginate fibers using the wet spinning method and confirmed the antibacterial properties of alginate fibers against both Gram-positive and Gram-negative pathogenic bacteria. Xue et al. [15] produced AgNPs on cotton fibers by in situ reductions of $\left[\mathrm{Ag}\left(\mathrm{NH}_{3}\right)_{2}\right]^{+}$with glucose, then the treated textiles were modified by alkylsilane with a long chain and claimed higher antibacterial activity against the Escherichia coli. Liu et al. [16] synthesized silver nanoparticles using solar irradiation and Nageia Nagi extract following the green chemistry and sustainable approach and assessed their antibacterial activity. Moreover, synthesis of AgNPs is being reported using variant natural leaves, for instance, bamboo [17], Chinese Holly [18], Gui Hua (Osmanthus Fragrans) [19], etc.

The nanoparticles offer multifunctionalities to the textiles are being sustained after repeated washing [20-22]. The nanoparticles are being used for a large variety of applications; besides their plenty of benefits, there are some shortcomings and health issues related to nanoparticles, as reviewed and reported recently [23]. However, silver has been reported as one of the safe antibacterial agents and nontoxic to the human body, which can kill harmful microorganisms [24]. The aim of this paper is to present the characterization of antibacterial, mothproofing, and electrical properties of wool textiles by the application of nanosilver colloid. Here, we have analyzed the commercially available silver nanoparticles (AgNPs) for their antibacterial and antistatic performance mainly. The wool textiles were pretreated by an enzyme protease in order to make the wool fiber surface welcoming to silver nanoparticles.

\section{Experimental}

2.1. Materials. The analytical-grade enzyme Savinase 16L was purchased from Novozymes Biopharmaceuticals, Ltd, China. The commercial-grade silver $\left(\mathrm{Ag}^{+}\right)$particle (AGS2YR-001) was provided by Shanghai Nano-Technology Ltd., China. The analytical-grade hydrogen peroxide $\left(\mathrm{H}_{2} \mathrm{O}_{2}\right)$ and sodium carbonate $\left(\mathrm{Na}_{2} \mathrm{CO}_{3}\right)$ were purchased from Chinese Medicine Group Chemical Reagent Co, Ltd., China. The analytical-grade sodium sulfite $\left(\mathrm{NaHSO}_{4}\right)$, sodium pyrophosphate $\left(\mathrm{Na}_{4} \mathrm{P}_{2} \mathrm{O}_{7}\right)$, and acetic acid $\left(\mathrm{C}_{2} \mathrm{H}_{4} \mathrm{O}_{2}\right)$ were purchased from Chemical Industry Group Chemical Reagent Co., Ltd., China. The analytical-grade Sodium chloride $(\mathrm{NaCl})$ was bought from Hangzhou Gao Jing Fine Chemical Industry Co., Ltd., China. The peptone, yeast powder, and powdered agar were provided by Base Bio-Tech Co., Ltd., Hangzhou, China. The strains of Gram-negative bacteria Klebsiella pneumoniae (K. pneumoniae; ATCC 4352) and Gram-positive bacteria Staphylococcus aureus (S. aureus; ATCC 6538) were taken from the College of Life Sciences, Donghua University, China. Tween 20 was provided by Hainan Zhongxin Chemical Co., Ltd. Shanghai, China.

Wool fiber or fabric samples were placed at a standard temperature (i.e., $20 \pm 2^{\circ} \mathrm{C}$ ) and humidity (i.e., $65 \pm 2 \%$ ) environment before all experiments for 24 hours to be moisture balanced. All the samples were kept in a dry bag. All fiber samples had a unit mass of $15 \mathrm{~g}$. The fabric samples were cut according to the test requirements. Liquor ratio of $1: 30$ was used in the experiment.

2.2. Coating of $\mathrm{H}_{2} \mathrm{O}_{2} /$ Protease with AgNPs. The percentage of enzyme protease was varied (i.e., $3 \%, 6 \%$, and 9\%) in surface treatment before incorporating silver nanoparticles, and the $\mathrm{pH}$ value was varied at the silver incorporation stage; $\mathrm{pH} 4$ and $\mathrm{pH} 7$ were used. The experiment was conducted as illustrated in Figure 1.

2.3. Characterization of Nanocoatings. The surface morphology of the fibers after treatment with protease and silver nanoparticles was determined by Scanning Electron Microscope (TM3000) with a magnification range of 2030000X from Hitachi, Japan. The SEM micrographs taken at a magnification of $2000 \mathrm{X}$ are presented.

The woolen samples treated with protease and silver nanoparticles were tested using the infrared spectra using the Nicolet 6700 Fourier Transform Infrared Spectrometer by US Thermo Fisher. The spectra were in the range of $4000 \mathrm{~cm}^{-1}$ to $400 \mathrm{~cm}^{-1}$. The change of the functional groups in the fiber before and after the wool fibers treatment was analyzed by the changes of the peaks and valleys in the spectrum.

2.4. Characterization of Electrical Properties. Fiber electricalspecific resistances of antistatic finish-treated fiber were determined by the fiber-specific resistance tester (XR-1A) from Changzhou Textile Instrument Ltd., China, with the 


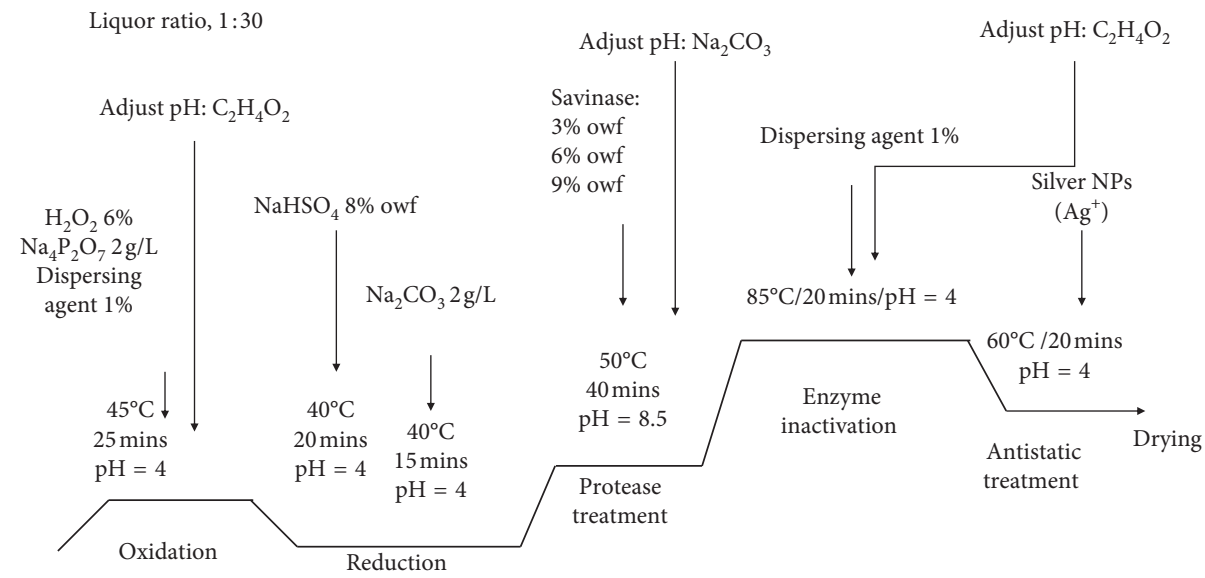

FIgURE 1: $\mathrm{H}_{2} \mathrm{O}_{2}$ /protease and silver NPs process with varying percentage of protease and with varying $\mathrm{pH}$.

resistance of $10^{6}-10^{13} \Omega$. The average volume resistivity $(\Omega \cdot \mathrm{cm})$ of a sample size of $15 \mathrm{~g}, 10$ sets, was measured. The testing of the samples was performed at standard conditions of $20 \pm 2^{\circ} \mathrm{C}$ and $65 \pm 3 \%$ relative humidity.

The fabric half-life and static voltage were measured by textile induction (fabric-induced) electrostatic tester (YG401) $10 \mathrm{kV} 100000 \mathrm{~s}$ from Ningbo Textile Instrument Factory, China, according to the Chinese standards FZ/T01042-1996 "Determination of electrostatic half-life of electrostatic properties of textile materials." The test conditions used were temperature $20^{\circ} \mathrm{C}$ and relative humidity, $30 \%-40 \%$.

2.5. Characterization of Washing Fastness. The washing fastness of silver nanocoated wool fibers was determined by following GB/T 3921.3-1997 Textiles-tests for color fastness-color fastness to washing. Nanocoated wool fibers were washed at $60^{\circ} \mathrm{C}$ in the washing liquor prepared by $2 \mathrm{~g} / \mathrm{L}$ of Tween 20 (a nonionic detergent) for 5 min under mild stirring of the washing machine. This was followed by rinsing wool fibers in cold water and then oven-dried at $80^{\circ} \mathrm{C}$. The nanocoated wool fibers were washed 20 times. The washing fastness of AgNPs on the nanocoated woolen fiber was evaluated by comparing the electrical properties AgNPs before and after washes.

2.6. Characterization of Antibacterial Property. The antimicrobial performance of wool specimens was quantitatively evaluated against Gram-negative bacterium Klebsiella pneumoniae (K. pneumoniae; ATCC 4352) and Grampositive bacterium Staphylococcus aureus ( $S$. aureus; ATCC 6538) according to the test method AATCC 1001999. Both K. pneumoniae and $S$ aureus were subcultured on agar. The agar was prepared according to the method described in our previous paper [22]. The wool specimens were placed on germ-containing agar plates, inoculated with $S$. aureus and $K$. pneumoniae. The wool samples were wetted with inoculum solution by using $\sim 0.5 \%$ of Tween 20 , a commercial nonionic agent. Antibacterial performance of wool specimens was calculated after 24 hours of contact time in terms of percent reduction of bacteria (R\%); mathematically, it can be expressed by the following equation:

$$
R \%=\frac{A-B}{A} \times 100
$$

where $R \%$ is the percent reduction of bacteria, $A$ is the number of bacterial colonies formed by untreated wool fiber, and $B$ is the number of bacterial colonies formed by treated wool fiber.

2.7. Characterization of Fiber Friction. The friction property of single fiber was tested by fiber friction coefficient tester (XCF-1A) with the precision of \pm 1 from Shanghai Institute, China. The static friction coefficient and kinetic friction coefficient of each fiber were recorded at the standard testing conditions (i.e., $20^{\circ} \mathrm{C}$ and $60 \% \mathrm{RH}$ ). The statistical data of the coefficient of kinetic friction were obtained and used in this study.

\section{Results and Discussion}

3.1. Effect on Surface Morphology of Wool Fibers. The surface morphology and the effect of treatment on the wool fibers were observed using the scanning electron microscopy (SEM) at 2000X magnification $(30 \mu \mathrm{m})$. The micrographs of the untreated samples are presented in Figure 2. From the micrographs, it can be observed that the untreated surface of the wool fibers is covered with tile-like arranged and intact scales. The edges of the scales are clearly visible.

Figure 2(a) shows the untreated fiber. Figures 2(b)-2(d) are wool treated with different percentages of protease incorporated with the same $8 \%$ o.w.f. of silver nanoparticles, all at $\mathrm{pH} 4$. Figure 2(e) shows the wool fiber treated with $6 \%$ protease and $8 \%$ o.w.f. silver nanoparticles at $\mathrm{pH} 7$. After the protease/treatment, it can be seen that the scale structures varied with the percentage of protease used, in which the scale protrusion and aggregation are decreased as protease used is decreased and they become less profound. The discontinuity of the scales is increased although the scales are not completely stripped but more profound on the fiber scale layers of the sample treated with $9 \%$ protease. Its scales are 


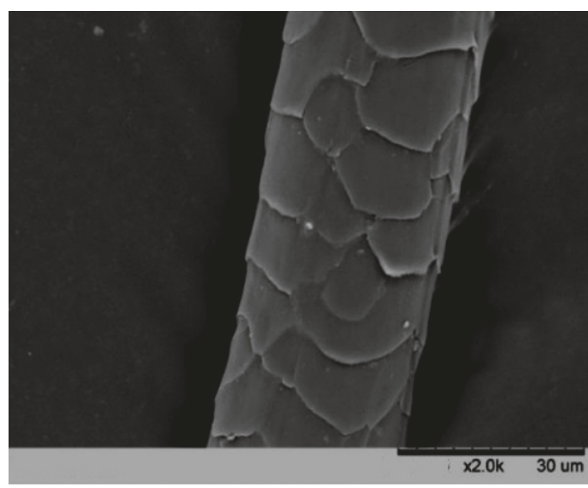

(a)

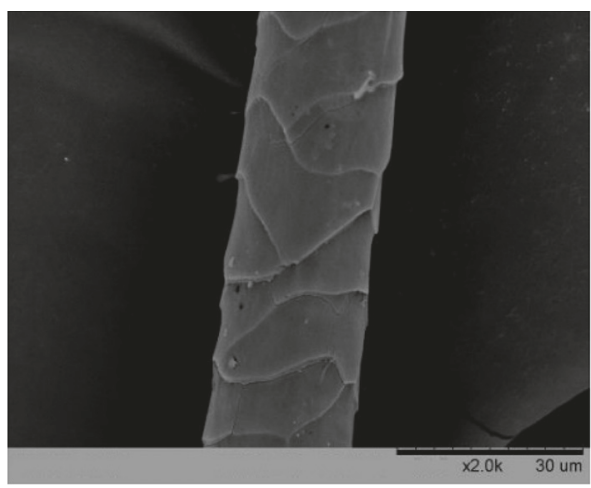

(c)

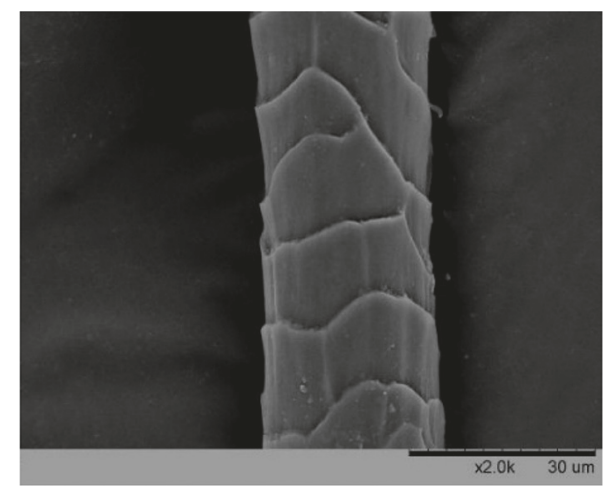

(b)

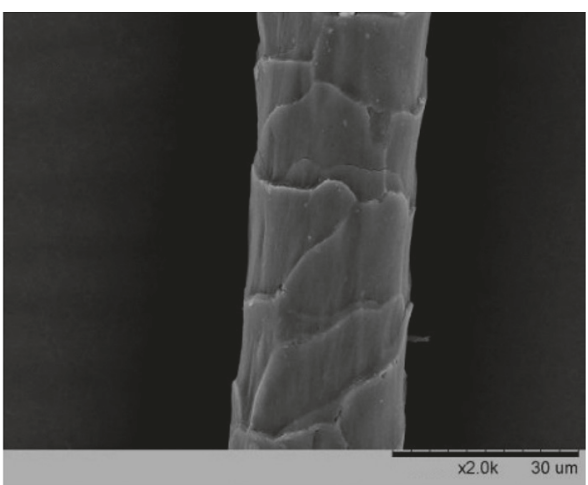

(d)

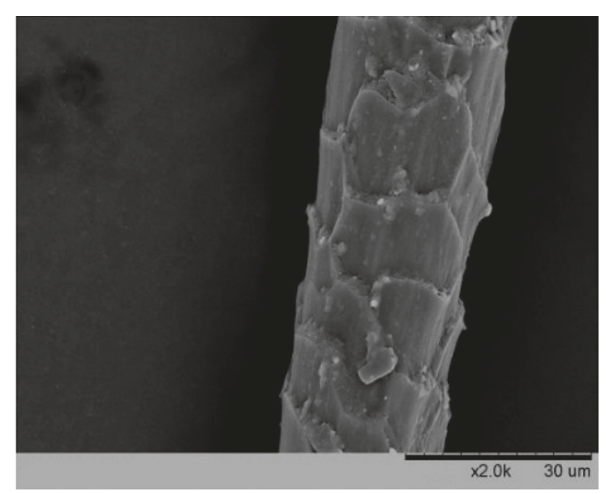

(e)

FIGURE 2: SEM micrographs of wool surfaces before and after treatment: (a) untreated wool fiber; (b) 3\% protease/silver NPs at pH = 4; (c) $6 \%$ protease/silver NPs at $\mathrm{pH}=4$; (d) $9 \%$ protease/silver NPs at $\mathrm{pH}=4$; (e) $6 \%$ protease/silver $\mathrm{NPs}$ at $\mathrm{pH}=7$.

degraded and fiber thinning is visible. It can be seen that it will form a layer of continuous hydrophilic film on the scale layer after coating antistatic agent, making the scale lines blurred and the whole body smooth, and only the local scales are not completely covered. The fibers treated at a higher $\mathrm{pH}$ (i.e., 7) reveal particles deposited onto the fiber surface, and the scales are further damaged. Therefore, raising $\mathrm{pH}$ can affect the fiber surface properties. Moreover, it can also clearly be seen that the amount of silver absorbed at lower $\mathrm{pH}$ is higher.

Wool fiber at $\mathrm{pH}$ higher than isoelectric point has a negative surface charge. This charge would act as an initial restrictive agent to sorption of anionic species. At a lower $\mathrm{pH}$, a significant proportion of internal amino groups are protonated, causing neutralization of this surface charge and absorption of the higher amount of AgNPs. It is also apparent that an increase in temperature leads to a higher load of silver on the fabrics due to the increase in kinetic energy. In alkaline conditions, silver ions seem to catalyze the degradation of cysteine, subsequently releasing $\mathrm{H}_{2} \mathrm{~S}$ and thus forming additional thiol groups, which are later converted into mercaptides.

3.2. Analysis of Infrared Spectra of Wool Fibers after Treatment. The Fourier transform infrared spectroscopy technique was used to analyze the wool fiber before and after treatment, in order to investigate the changes in the fiber structure. The results are shown in Figure 3. The band frequencies of $1071 \mathrm{~cm}^{-1}$ and $1040 \mathrm{~cm}^{-1}$ were assigned for 


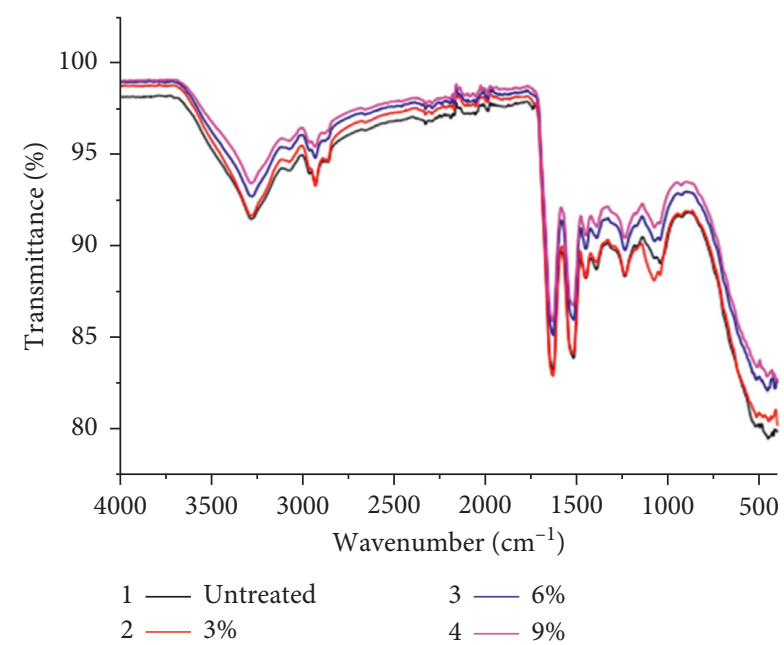

Figure 3: The Infrared Spectra of wool fibers after treatment with protease/silver NPs.

cysteic acid $-\mathrm{SO}_{3}$ - and cysteine monoxide $-\mathrm{SO}^{-}$-, respectively, and the changes in their transmittances were observed.

The eminence and the intensity of the $\mathrm{SO}_{3}$ - vibrational bands at $1040 \mathrm{~cm}^{-1}$ were strong indications that the disulfide bonds S-S had been cleaved and subsequently oxidized to cysteic acid residues by hydrogen peroxide during the pretreatment process. It should also be noted that the increase in the percentage of protease (at same $\mathrm{pH}$ i.e., 4) causes further changes to occur, which has converted cysteic acid into cysteine monoxides and thus shifted vibrational bands at $1073 \mathrm{~cm}^{-1}$ and $1075 \mathrm{~cm}^{-1}$ for $6 \%$ and $9 \%$, respectively. This indicates that sulfur and sulfur compounds play a key role in the surface treatment of wool fiber, and therefore, wool fibers from sulfur-deficient sheep may require mild processing.

Further investigations were done to assess the changes due to wool fiber treatment in the fiber structure by increasing the $\mathrm{pH}$ from 4 to 7 . The infrared spectra of the fiber before and after fiber treatment were studied by using Fourier transform infrared spectroscopy. The results are shown in Figure 4. It can be seen that by increasing the $\mathrm{pH}$, the transmittance value was also increased, which suggests possible degradation of sulfur and sulfur-based radicals on the surface of the wool fiber. Both the band frequencies of $1073 \mathrm{~cm}^{-1}$ and $1040 \mathrm{~cm}^{-1}$ were increased in terms of transmittance, suggesting the fiber surficial degradation.

3.3. Antibacterial Performance. The antibacterial performance of nanocoated fabrics was associated with the interaction in between nanoparticles and the proteins, especially at thiol (sulfhydryl, $-\mathrm{SH}$ ) groups. Since this moiety helps proteins to be entangled with it, likewise, this moiety have helped the enzyme to be adhered with it. On the adhesion, the cellular metabolism would have been inhibited causing the death of the microorganisms. An excellent antibacterial activity was achieved by wool fibers, as shown in Table 1.

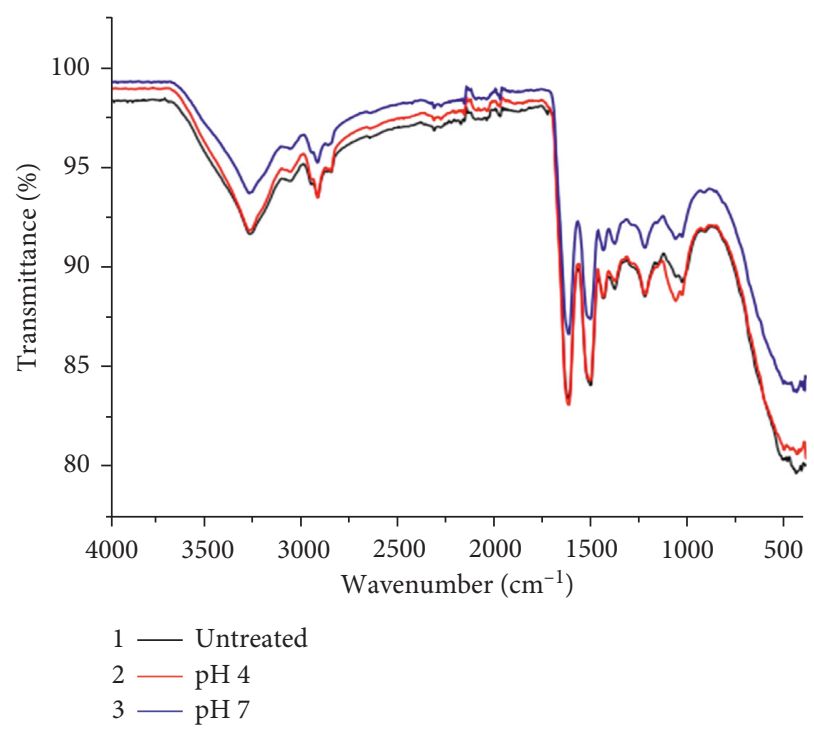

FIGURE 4: The effect of $\mathrm{pH}$ and Analysis of Infrared Spectra of wool fibers after treatment.

It was manifested that the fabric sample coated with $6 \%$ Pro./AgNPs at $\mathrm{pH} 7$ offered the poorer antibacterial property as compared to other samples. Although this antibacterial is a bit lesser than the antibacterial performance obtained by other samples at a $\mathrm{pH}$ of 4 , yet it is also considerable.

3.4. Effect on Volume Resistivity of Wool Fibers. Normally, a fiber with the resistance of $1 \times 10^{10} \Omega \cdot \mathrm{cm}$ at RH $65 \%$ and $20^{\circ} \mathrm{C}$ conditions can be considered as antistatic. The specific resistance of the synthetic fiber is more than $1 \times$ $10^{13} \Omega \cdot \mathrm{cm}$, and for wool fiber, it is about $1 \times 10^{11} \Omega \cdot \mathrm{cm}$. The specific test results are shown in Figure 5.

The volume resistivity of the samples treated with $3 \%$ protease/silver nanoparticles at $\mathrm{pH} 4$ had the lowest resistance, while the samples treated with $6 \%$ protease/silver nanoparticles at high $\mathrm{pH} 7$ had higher resistivity compared to others. This indicates that raising the $\mathrm{pH}$ can lead to low resistivity due to the effect of wool surface properties that are affected by high a $\mathrm{pH}$. The damage of the cuticle cells may expose the inner parts of the fiber thus affecting its properties such as ion association on the fiber. As early stated, the amount of silver absorbed at a lower $\mathrm{pH}$ is higher, thus the lower resistance at a lower $\mathrm{pH}$ is obvious.

3.5. Effect on Half-Life Period of Wool Fibers. Specific static half-life test results are shown in Figure 6.

The antistatic characteristics of the treated samples revealed that the electrostatic half-life was short in the samples treated using $3 \%$ protease. This is due to the quick dissipation of accumulated charges facilitated by more silver nanoparticles. The electrostatic half-life of the other samples also reduced significantly compared with $3 \%$ protease indicating that surface modification by scale stripping and treatment at high $\mathrm{pH}$ can affect antistatic properties of wool. The effect of the scales on the loading of silver nanoparticles is that due to the scale layer composition which is made up of 
TABLE 1: The antibacterial performance of wool fibers.

\begin{tabular}{ccccc}
\hline Bacteria & & Untreated & $3 \%, 6 \%$, and $9 \%$ Protease/AgNPs & $6 \%$ Pro./AgNPs at pH $=7$ \\
\hline & Start & $1.6 \times 105$ & $1.6 \times 105$ & $1.6 \times 105$ \\
Staphylococcus aureus $(\mathrm{CFU} / \mathrm{mL})$ & After $24 \mathrm{~h}$ & $4.1 \times 107$ & $<10$ & $5.3 \times 103$ \\
& $\mathrm{R} \%$ & - & $99.99 \%$ & $96.68 \%$ \\
& Start & $1.7 \times 105$ & $1.7 \times 105$ & $1.7 \times 105$ \\
Klebsiella pneumoniae $(\mathrm{CFU} / \mathrm{mL})$ & After $24 \mathrm{~h}$ & $5.7 \times 107$ & $<10$ & $7.8 \times 103$ \\
& $\mathrm{R} \%$ & - & $99.99 \%$ & $95.41 \%$ \\
\hline
\end{tabular}

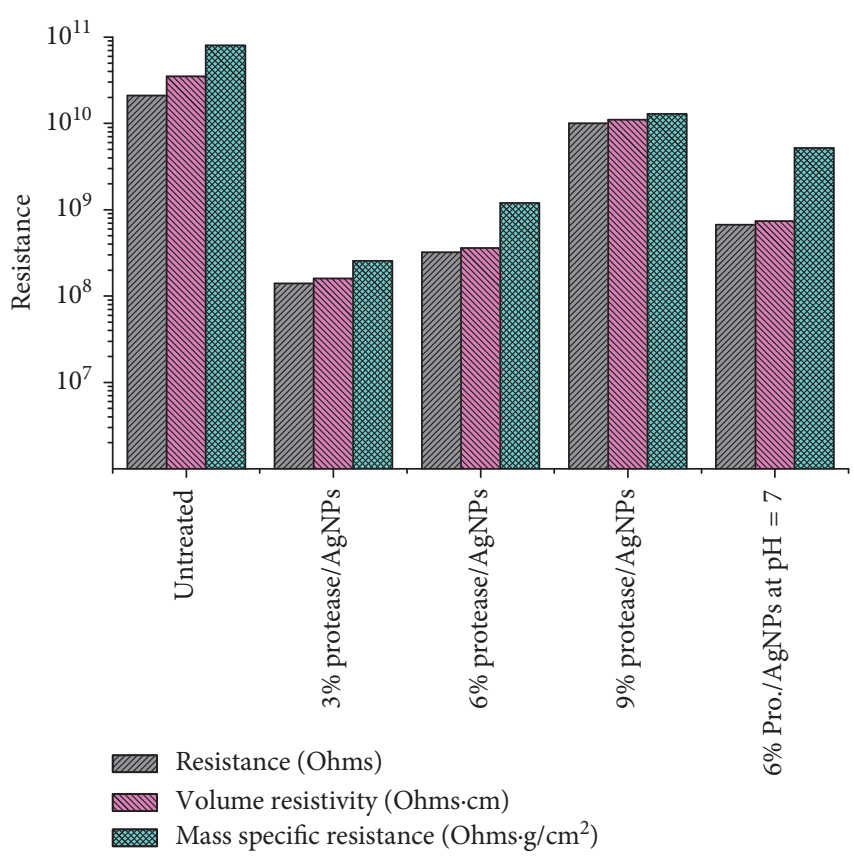

FIGURE 5: The volume resistivity of treated wool fibers.

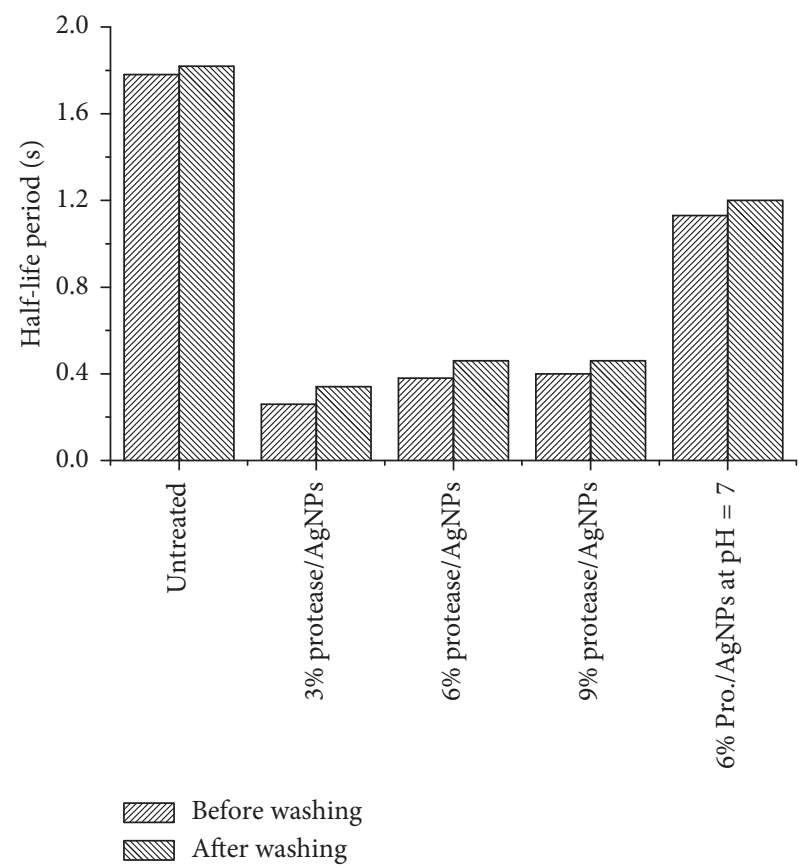

Figure 6: The half-life period of wool after treatment. cysteine which helps bind the silver nanoparticles on the surface. It can be seen that the stripping of the scale layer reduces the electrostatic half-life of the fabric to a certain extent. It was observed that if the treated samples were washed with soap twenty times, the half-life will rise slightly although the treatment had a durable antistatic effect.

3.6. Effect on Interaction Voltage of Wool Fibers. The antistatic treatment of friction-induced electrostatic voltage test is shown in Figure 7.

It can be seen that by using $3 \%, 6 \%$, and $9 \%$ protease are all effective enough to reduce friction on the wool surface and even using less protease (i.e., 3\%) incorporated with silver nanoparticles can significantly improve antistatic properties of wool. At higher $\mathrm{pH}$, the wool surface can be affected and its antistatic properties are compromised. The electrostatic voltage dropped from $7000 \mathrm{~V}$ to $1400 \mathrm{~V}$ and even as low as $200 \mathrm{~V}$. Incorporating silver nanoparticles and scale stripping can make wool fiber to have good antistatic properties even after washing in soap twenty times.

3.7. Effect on the Friction Coefficient. The surface of the wool fibers is normally covered with scales, and these scales can degenerate to different degrees or levels by varying the percentage of protease used in scale stripping. After the treatment using a high percentage of protease, the outer layer of the scales was almost completely stripped and the surface became smoother. Therefore, the surfaces of fibers with less stripped scales had higher friction but were still much improved as compared with the untreated fibers. The wool fiber friction coefficient test results are shown in Figure 8 .

It can be also noted that scale stripping can achieve good frictional effects. These are indicated by the value of the difference of the coefficient of friction along the scale direction and/or against scales direction, which is greatly reduced. For that reason, incorporating silver nanoparticles in protease treatment of wool fibers was better at a lower percentage of protease and at a lower $\mathrm{pH}$ used. Scale stripping affects the S-S bonds and side groups on the wool cuticle that are essential in the loading of silver nanoparticles on wool.

\section{Conclusions}

The disulfide bond S-S is oxidized to cysteic acid residues by hydrogen peroxide, and increasing percentage of protease causes further changes to occur which converts cysteic acid 


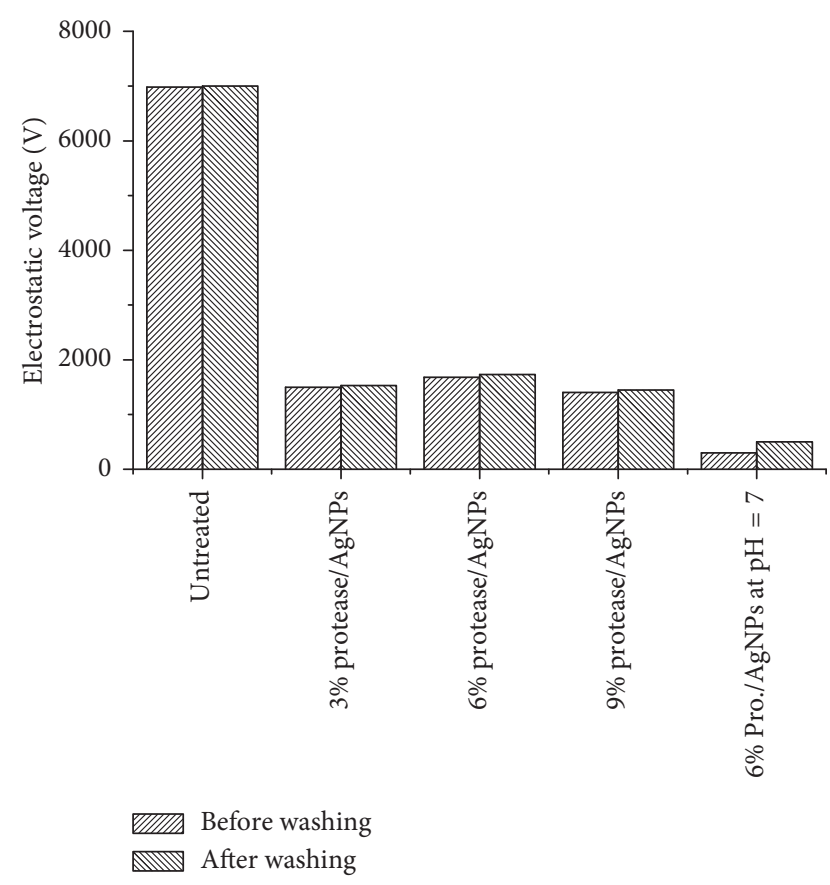

Figure 7: The interaction voltage of wool after treatment.

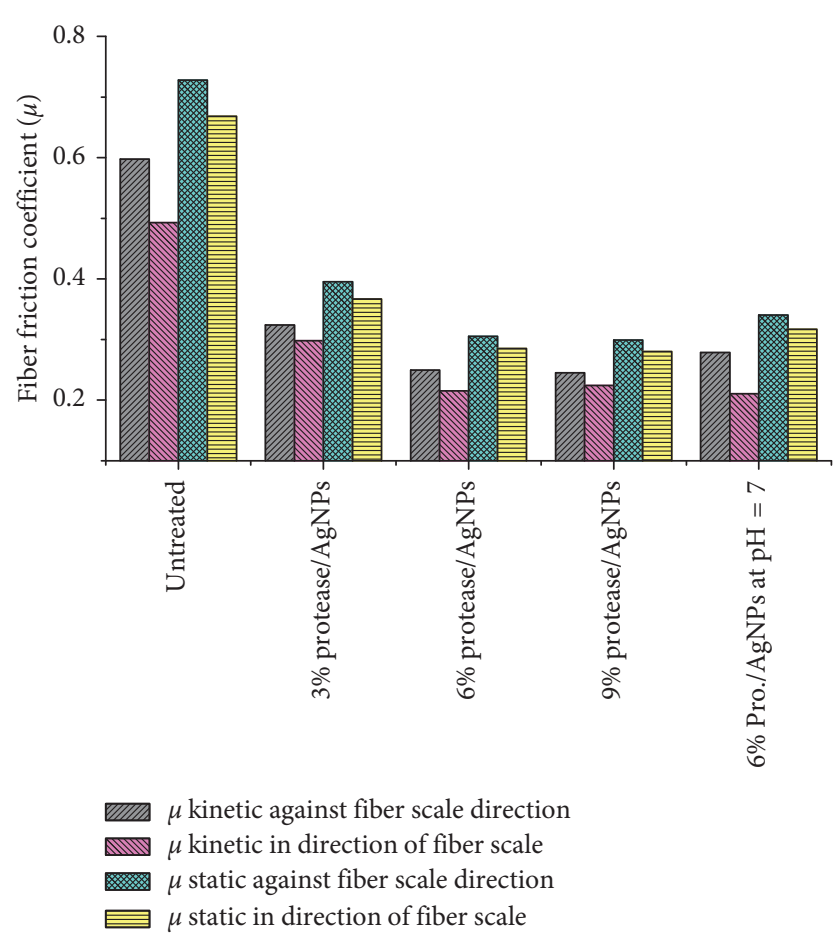

FIgURE 8: The fiber friction of treated wool fibers.

into cysteine monoxides of vibrational bands at $1073 \mathrm{~cm}^{-1}$ and $1075 \mathrm{~cm}^{-1}$ for $6 \%$ and $9 \%$ protease all at $\mathrm{pH} 4$. This points out that sulfur and sulfur compounds play a key role in the surface treatment of wool fiber, and therefore, wool fibers from sulfur-deficient sheep may require mild processing. The volume resistivity is affected by the $\mathrm{pH}$. High $\mathrm{pH}$ caused too high resistivity, while low $\mathrm{pH}$ had good conductivity; therefore, silver nanoparticles give better results if incorporated at $\mathrm{pH} 4$.

Half-life and electrical voltage were all improved after treatment. The surface of the wool fibers is normally covered with scales, and these scales can degenerate to different degrees or levels by varying the percentage of protease used in scale stripping. After the treatment using a high percentage of protease, the outer layer of the scales was almost completely stripped and the surface became smoother. Therefore, the surfaces of fibers with less stripped scales had higher friction but were still much improved as compared with the untreated fibers. It can be also noted that scale stripping can achieve good frictional effects. These are indicated by the value of the difference of the coefficient of friction along the scale direction or against scales direction, which is greatly reduced. Therefore, incorporating silver nanoparticles in protease treatment of wool fibers was better at a lower $\mathrm{pH}$ and a lower percentage of protease used. Scale stripping affects the S-S bonds and side groups on the wool cuticle that are essential in the loading of silver nanoparticles on wool.

\section{Data Availability}

The data used to support the findings of this study are available from the corresponding author upon request.

\section{Conflicts of Interest}

The authors declare no conflicts of interest.

\section{Acknowledgments}

All laboratory staff of the Department of Textile Engineering, Donghua University, China, is gratefully acknowledged. The authors would like to thank the Shanghai Government Scholarship Council for their financial support.

\section{References}

[1] A. N. Khoso, H. Memon, M. Hussain, A. N. Sanbhal, and A. Z. Abro, "Production and characterization of wool and hair fibers in highlands of Baluchistan, an economic and sustainable approach for Pakistan," Key Engineering Materials, vol. 671, pp. 473-482, 2016.

[2] H. Memon, H. Wang, and E. Langat, "Determination and characterization of the wool fiber yield of Kenyan sheep breeds: an economically sustainable practical approach for Kenya," Fibers, vol. 6, no. 3, p. 55, 2018.

[3] R. Morent, N. De Geyter, J. Verschuren, K. De Clerck, P. Kiekens, and C. Leys, "Non-thermal plasma treatment of textiles," Surface and Coatings Technology, vol. 202, no. 14, pp. 3427-3449, 2008.

[4] R. Molina, P. Jovančić, D. Jocić, E. Bertran, and P. Erra, "Surface characterization of keratin fibres treated by water vapour plasma," Surface and Interface Analysis, vol. 35, no. 2, pp. 128-135, 2003.

[5] H. Barani, M. Montazer, A. Calvimontes, and V. Dutschk, "Surface roughness and wettability of wool fabrics loaded with silver nanoparticles: influence of synthesis and application 
methods," Textile Research Journal, vol. 83, no. 12, pp. 1310-1318, 2013.

[6] G. S. Malkov and E. R. Fisher, "Pulsed plasma enhanced chemical vapor deposition of poly (allyl alcohol) onto natural fibers," Plasma Processes and Polymers, vol. 7, no. 8, pp. 695-707, 2010.

[7] D. Chen, L. Tan, H. Liu, J. Hu, Y. Li, and F. Tang, "Fabricating superhydrophilic wool fabrics," Langmuir, vol. 26, no. 7, pp. 4675-4679, 2010.

[8] S. J. Meade, J. P. Caldwell, A. J. Hancock, K. Coyle, J. M. Dyer, and W. G. Bryson, "Covalent modification of the wool fiber surface: the attachment and durability of model surface treatments," Textile Research Journal, vol. 78, no. 12, pp. 1087-1097, 2008.

[9] H. Y. Ki, J. H. Kim, S. C. Kwon, and S. H. Jeong, "A study on multifunctional wool textiles treated with nano-sized silver," Journal of Materials Science, vol. 42, no. 19, pp. 8020-8024, 2007.

[10] A. Varesano and C. Tonin, "Improving electrical performances of wool textiles: synthesis of conducting polypyrrole on the fiber surface," Textile Research Journal, vol. 78, no. 12, pp. 1110-1115, 2008.

[11] C. X. Wang, J. C. Lv, Y. Ren et al., "Surface modification of polyester fabric with plasma pretreatment and carbon nanotube coating for antistatic property improvement," Applied Surface Science, vol. 359, pp. 196-203, 2015.

[12] S. T. Dubas, P. Kumlangdudsana, and P. Potiyaraj, "Layer-bylayer deposition of antimicrobial silver nanoparticles on textile fibers," Colloids and Surfaces A: Physicochemical and Engineering Aspects, vol. 289, no. 1-3, pp. 105-109, 2006.

[13] M. S. Khalil-Abad and M. E. Yazdanshenas, "Superhydrophobic antibacterial cotton textiles," Journal of Colloid and Interface Science, vol. 351, no. 1, pp. 293-298, 2010.

[14] L. Yu, H. Memon, P. Bhavsar, and S. Yasin, "Fabrication of alginate fibers loaded with silver nanoparticles biosynthesized via Dolcetto grape leaves (Vitis vinifera cv.): morphological, antimicrobial characterization and in vitro release studies," Materials Focus, vol. 5, no. 3, pp. 216-221, 2016.

[15] C. H. Xue, J. Chen, W. Yin, S. T. Jia, and J. Z. Ma, "Superhydrophobic conductive textiles with antibacterial property by coating fibers with silver nanoparticles," Applied Surface Science, vol. 258, no. 7, pp. 2468-2472, 2012.

[16] Y. Liu, M. Hussain, H. Memon, and S. Yasin, "Solar irradiation and Nageia Nagi extract assisted rapid synthesis of silver nanoparticles and their antibacterial activity," Digest Journal of Nanomaterials and Biostructures, vol. 10, no. 3, pp. 10191024, 2015.

[17] S. Yasin, L. Liu, and J. Yao, "Biosynthesis of silver nanoparticles by bamboo leaves extract and their antimicrobial activity," Journal of Fiber Bioengineering and Informatics, vol. 6, no. 6, pp. 77-84, 2013.

[18] N. Ullah, S. Yasin, Z. Abro, L. Liu, and Q. Wei, "Mechanically robust and antimicrobial cotton fibers loaded with silver nanoparticles: synthesized via Chinese holly plant leaves," International Journal of Textile Science, vol. 3, no. 1, pp. 1-5, 2014.

[19] N. Ullah, D. Li, C. Xiaodong et al., "Photo-irradiation based biosynthesis of silver nanoparticles by using an ever green shrub and its antibacterial study," Digest Journal of Nanomaterials and Biostructures, vol. 10, pp. 95-105, 2015.

[20] H. Memon, S. Yasin, N. A. Khoso, and S. Memon, "Study of wrinkle resistant, breathable, anti UV nanocoated woven polyester fabric," Surface Review and Letters, vol. 23, no. 3, article 1650003, 2016.
[21] H. Memon, N. Kumari, A. W. Jatoi, and N. A. Khoso, "Study of the indoor decontamination using nanocoated woven polyester fabric," International Nano Letters, vol. 7, no. 1, pp. 1-7, 2017.

[22] H. Memon and N. Kumari, "Study of multifunctional nanocoated cold plasma treated polyester cotton blended curtains," Surface Review and Letters, vol. 23, no. 5, article 1650036, 2016.

[23] H. Memon, S. Yasin, N. A. Khoso, and M. Hussain, "Indoor decontaminating textiles by photo catalytic oxidation-a review," Journal of Nanotechnology, vol. 2015, Article ID 104142, 9 pages, 2015.

[24] D. P. Dowling, A. J. Betts, C. Pope, M. L. McConnell, R. Eloy, and M. N. Arnaud, "Anti-bacterial silver coatings exhibiting enhanced activity through the addition of platinum," Surface and Coatings Technology, vol. 163-164, pp. 637-640, 2003. 

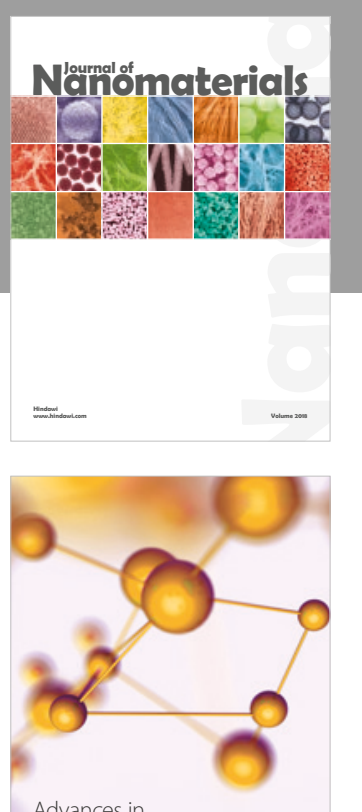

Physical Chemistry
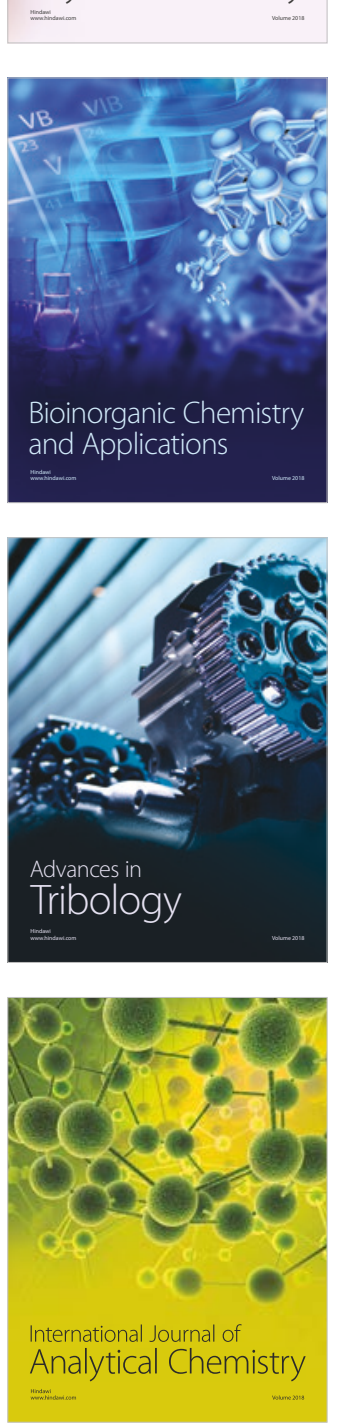

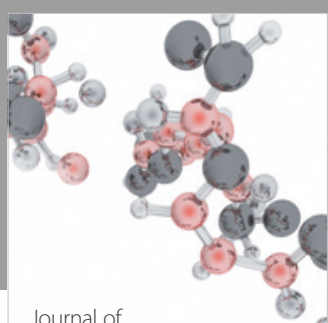

Analytical Methods

in Chemistry

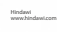

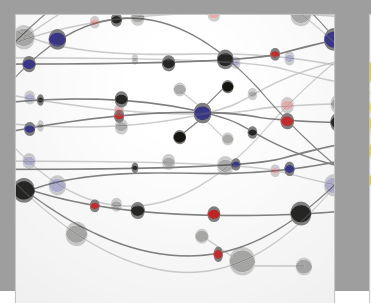

The Scientific World Journal

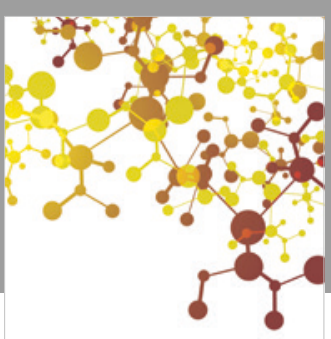

Journal of

Applied Chemistry
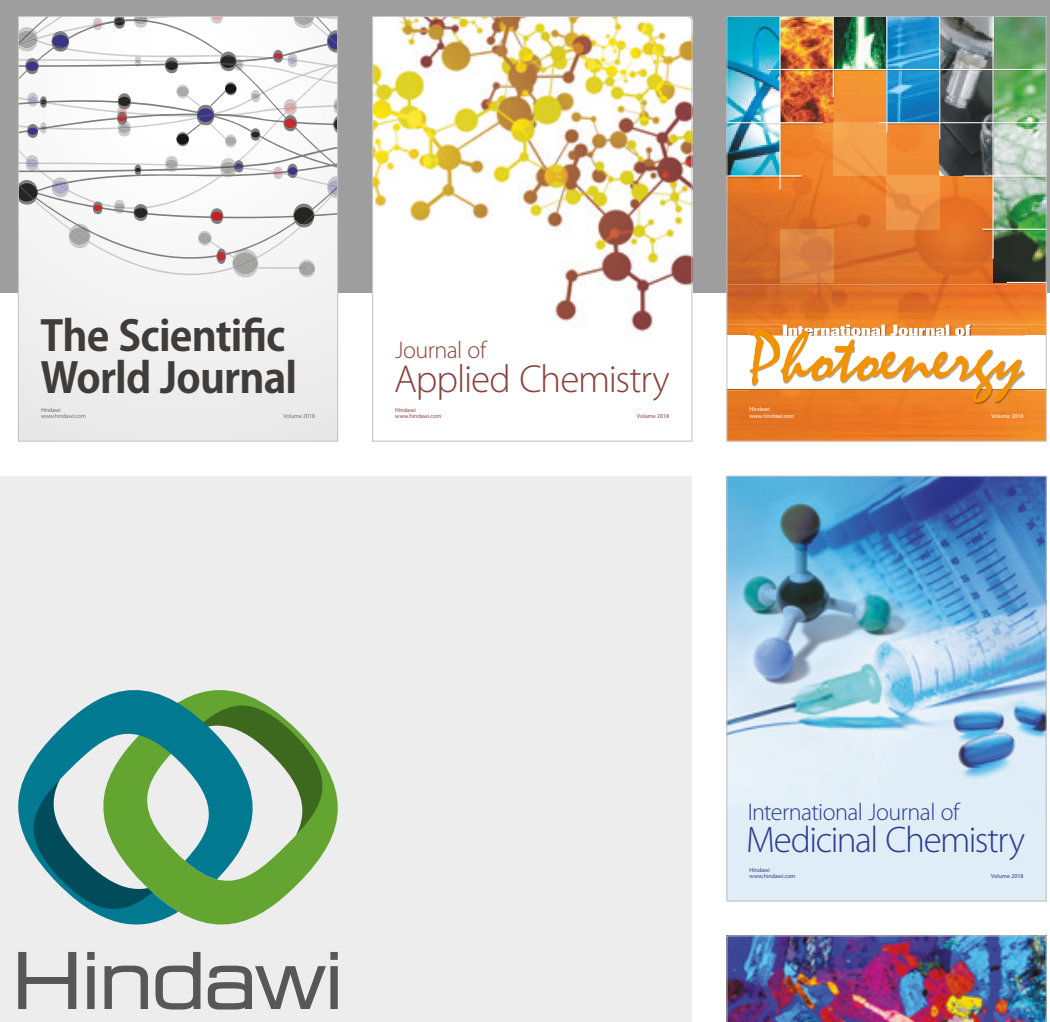

Submit your manuscripts at

www.hindawi.com
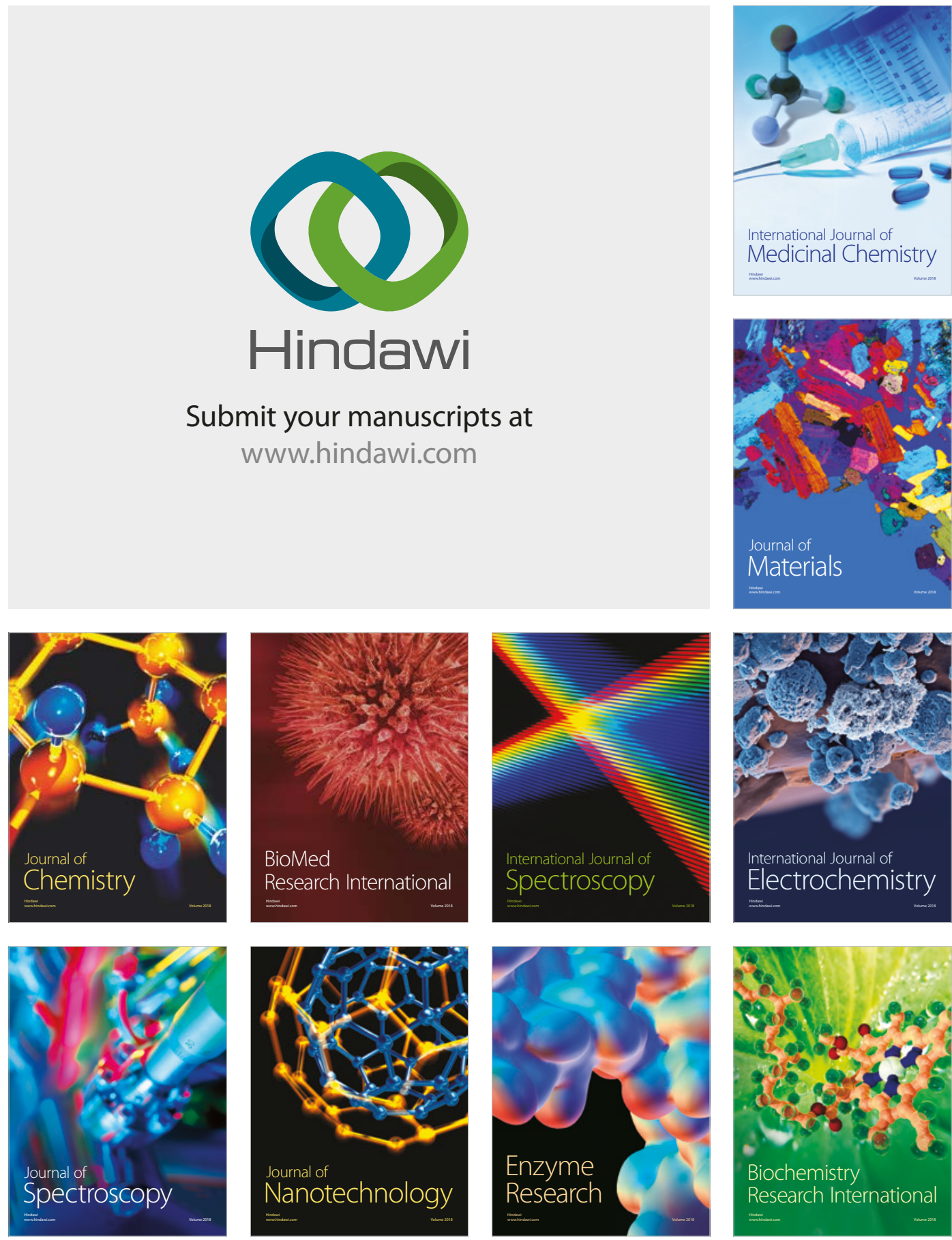
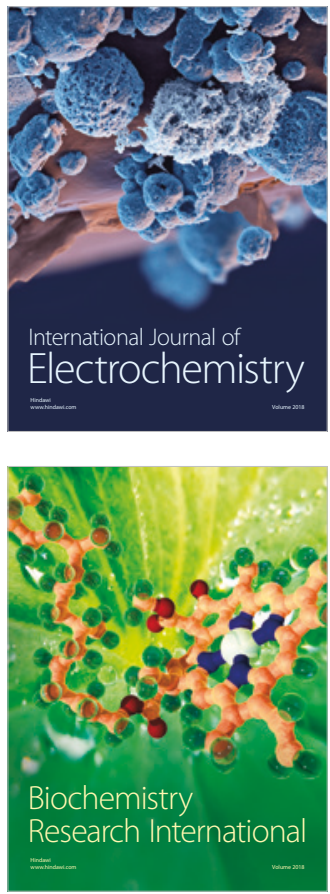